\title{
Simultaneous Effects of Aerobic Training and Berberine Chloride on Plasma Glucose, IL-6 and TNF- $\alpha$ in Type 1 Diabetic Male Wistar Rats
}

\author{
Javad Ramezani ${ }^{1}$, Mohammad Ali Azarbayjani*2 ${ }^{* 2}$, Maghsoud Peeri ${ }^{2}$ \\ 1- Ph.D. Student, Department of Exercise Physiology, Central Tehran Branch, Islamic Azad University, Tehran, Iran \\ 2- Professor, Department of Exercise Physiology, Central Tehran Branch, Islamic Azad University, Tehran, Iran
}

\section{A B S T R A C T}

Background and Objectives: Aerobic training and berberine chloride include antioxidant and anti-inflammatory characteristics. In the current study, simultaneous effects of aerobic training and berberine chloride on plasma glucose, IL6 and TNF- $\alpha$ were investigated in type 1 diabetic male Wistar rats.

Materials and Methods: In this experimental study, 64 male Wistar rats were randomly divided into eight groups $(n=8)$, including healthy control, diabetic control, diabetic-berberine (15 and $30 \mathrm{mg} / \mathrm{kg}$ ), diabetic-training, diabetictraining-berberine (15 and $30 \mathrm{mg} / \mathrm{kg}$ ) and health-trained. Diabetes was induced using a single intraperitoneal injection (IP) of streptozotocin (STZ) of $60 \mathrm{mg} / \mathrm{kg}$ body weight (BW). The training schedule included running on a treadmill for six weeks, five sessions a week and daily intakes of berberine using gavage. The IL- 6 and TNF- $\alpha$ values were assessed using enzyme-linked immunosorbent assay (ELISA) method.

Results: Results showed that the glucose concentration in diabetic groups with aerobic training and intake of berberine simultaneously was significantly lower than that in the diabetic control group $(P<0.05)$. Plasma IL-6 in the diabetic control group significantly increased, compared to that in the normal control group $(P<0.05)$. In diabetic groups that received the two treatments simultaneously, IL-6 significantly increased, compared to that in the diabetic control group $(P<0.05)$. The quantity of TNF- $\alpha$ in the diabetic control group was significantly higher than that in the normal control group $(P<0.05)$. The plasma level of TNF- $\alpha$ significantly decreased in all treatment groups, compared to that in the diabetic control group $(P<0.05)$.

Conclusions: Combined effects of berberine chloride use and aerobic training on blood glucose, IL- 6 and TNF- $\alpha$ are more evident than their individual effects. Furthermore, a dose of $30 \mathrm{mg} / \mathrm{kg}$ of berberine chloride included a greater effect on the highlighted blood parameters, compared to that a dose of $15 \mathrm{mg} / \mathrm{kg}$ of berberine chloride did.

Keywords: Type 1 Diabetes, Aerobic training, Berberine chloride, IL-6, TNF- $\alpha$

\section{Introduction}

Diabetes mellitus is a chronic and progressive metabolic disorder that is currently a public health problem and one of the most important causes of mortality in the world (1). Type 1 diabetes (T1D), which includes approximately $5-10 \%$ of the diabetic cases, is an autoimmune disorder caused by abnormalities in the function or degradation of pancreatic beta-cells (2). This is dependent on cellular infiltration and inflammatory responses in Langerhans Island cells within the pancreas (3). Cellular components of this infiltration include monocytes, macrophages, and $\mathrm{CD}^{4+}$ and $\mathrm{CD}^{8+} \mathrm{T}$ cells (4). Balances between T-helper 1 (Th1) and Th2 cells are essential in the pathogenesis of this disease (5). Cytokines play important roles in the development and activation of the immune cells as they act as cellsignaling molecules, especially in autoimmune diseases such as type 1 diabetes (3). Plasma levels of pro-inflammatory and Th1 cytokines such as interleukin 1 beta (IL-1 $\beta$ ), IL-2, IL-6, IL-12, tumor necrosis factor alfa (TNF- $\alpha$ ) and interferon gamma (IFN- $\gamma$ ) may be upregulated in patients with T1D (3). 
The IL-6 is most often classified as a proinflammatory cytokine. However, IL-6 includes antiinflammatory properties as well (6). Evidence shows that IL-6 is regulated by muscle contractions (7-9). The IL- 6 anti-inflammatory effects are imposed by inhibiting TNF- $\alpha$ and IL- $1 \beta$ and activating IL-1ra and IL-10 (10). Furthermore, TNF- $\alpha$ is believed to play an important role as an inflammatory cytokine in autoimmune type 1 diabetes. In Vitro studies on isolated Islets of Langerhans have shown that TNF- $\alpha$ is directly involved in degradation of beta-cells (11). Moreover, in vivo studies have shown that this cytokine includes deep inflammatory effects, including a direct effect, on antigen-presenting cells (APCs) and T-cell lymphocytes (12).

In recent decades, herbs and their active components have been widely used in the treatment of diabetes, particularly in T2D (13). Of these active components in herbal plants, berberine is an isoquinoline alkaloid that exhibits promising potential for its potent anti-inflammatory (14) and hypoglycemic effects (15). However, exact berberine effects on serum glucose levels in T1D patients remain unknown. Use of oral hypoglycemic agents for the treatment of T1D is still in its early stages. Berberine has been shown to include hypoglycemic and insulin-sensitizing effects in high-fat diet and streptozocin-induced diabetic rats (16). Berberine is found in many herbal plants, such as Hydrastis Canadensis (Goldenseal), Rhizoma coptidis (Huang Lian), Berberis vulgaris (barberry) and B. aristata (tree turmeric) widely used in Chinese traditional medicine $(17,18)$. Iran is the largest producer of barberries in the world. Barberries can be used as one of the most important medications in controlling and treating diabetes. Previous studies have shown that berberine chloride includes negative regulation of pro-inflammatory cytokines such as IFN- $\gamma$, TNF- $\alpha$, and IL-6 in animal models (19,20). Recently, berberine chloride at doses of $50 \mathrm{mg} / \mathrm{kg}$ for 45 days have been shown to significantly decrease TNF- $\alpha$ (21). Other studies have revealed that the lowest dose of berberine chloride (as an antioxidant and antiinflammatory agent) is $50 \mathrm{mg} / \mathrm{kg}(21,22)$. In the current study, berberine chloride doses of 15 and 30 $\mathrm{mg} / \mathrm{kg}$ were used to compare the interactive effects of the chemical and aerobic training.

Physical activity is another way of decreasing blood glucose in diabetics. Evidence suggests that physical activity reduces the progression of impaired glucose tolerance (23). the treadmill training program has been demonstrated to decrease plasma glucose concentrations $5 \mathrm{~min}$ after the glucose challenge (24). Research has shown that circulating IL-6 levels increase in an exponential mode (up to 100-fold) in response to exercises and decrease post exercises (25). The magnitude by which plasma IL-6 increases is associated to the exercise duration and intensity, the muscle mass involved in mechanical works and the endurance capacity (25). Duration of exercise is the most importantly unique factor that determines the magnitude of the systemic IL-6 response. The longer the duration of exercises, the further systemic IL-6 responses. Following intense exercises such as running at $75 \%$ of $\mathrm{VO}_{2}{ }^{\text {max }}$, the basal plasma IL-6 may increase 5-folds after $30 \mathrm{~min}$. However, plasma IL-6 concentration may increase up to 100 -fold after a marathon (26). The exercise-induced an increase in plasma IL-6 is followed by increased circulating levels of well-known anti-inflammatory cytokines such as IL-1ra and IL-10 (27). Furthermore, infusion of IL-6 to healthy donors mimics the exercise response of IL-1ra and IL-10 and enhances systemic levels of cortisol (28). The IL-1ra inhibits IL-1b signal transduction (29) and IL-10 is able to inhibit synthesis of pro-inflammatory cytokines such as TNF$\alpha$ (26). However, other studies have shown no decreases in TNF- $\alpha$ (30). Therefore, the aim of the current study was to investigate interactive effects of aerobic training and low-doses of berberine chloride on plasma glucose, IL-6, and TNF- $\alpha$ in streptozocin (STZ) induced diabetic male Wistar rats.

\section{Materials and Methods}

Animals: In this experimental study, 64 male Wistar rats (240-280 gr) were purchased from the Pasteur Institute of Iran, Tehran, Iran, and transferred to the Animal Room of the International Campus, Shahid Sadoughi University of Medical Sciences, Yazd, Iran. All standard parameters, including temperature condition $\left(24 \pm 1^{\circ} \mathrm{C}\right)$, relative humidity $(55 \pm 3 \%)$, free access to water, standard special diet (Behparvar, Iran) and a dark/light cycle (12/12 h) were included. Animals were housed in special polycarbonate cages for adaptation to the new environment for two weeks. To acquaint with the treadmill in the adaptation period, animals walked on the treadmill five days a week, each time for 5-10 
min at a speed of $4-5 \mathrm{~m} / \mathrm{min}$. Then, rats were randomly assigned to eight groups ( $n=8$ per group). Groups were matched based on the BW. The experimental type 1 diabetes was induced using intraperitoneal (IP) injections of $60 \mathrm{mg} / \mathrm{kg}$ per BW of fresh streptozocin solution ( $\mathrm{pH}$ 4.5) (Sigma, USA) dissolved in $0.1 \mathrm{M}$ of citrate buffer (31). An equivalent volume of normal saline solution was injected into two non-diabetic groups. To avoid severe drops in blood glucose after STZ injection, rats were provided with $5 \%$ glucose instead of water (21). Induced diabetes was verified after three days by measuring glucose in blood samples collected from tail veins using the glucocard-01 device (ARKRAY, Japan). Rats with a blood glucose level of $300 \mathrm{mg} / \mathrm{dl}$ or greater were included in the study as diabetic animals. The day of blood glucose test was set as zero. The experimental groups in this study included: 1) normal control group, 2) diabetic control group, 3 ) diabetic and berberine chloride group (15) [D-Br (15 $\mathrm{mg})$, 4) diabetic and berberine chloride group (30) [D-Br (30 mg)], 5) diabetic and aerobic training group [D-AT], 6) diabetic, aerobic training and berberine chloride group (15) [D-AT-Br (15 mg)], 7) diabetic, aerobic training and berberine chloride group $(30 \mathrm{mg})$ [D-AT-Br (30 mg)], and 8) healthy and aerobic training group (H-AT).

Aerobic training protocol: In the present study, a moderate training intensity $(55-50 \%$ maximum consumed oxygen) and physiological efficacy were used (Table 1) (32). Training groups trained for six weeks with a 3-day exercise on a treadmill and a 1day rest. In each training session, 5 min of warming up and $5 \mathrm{~min}$ of cooling down were used at a speed of 4-5 $\mathrm{m} / \mathrm{min}$; added to the main training time. Speed and duration of training gradually increased according to Table 1. No electrical shocks were used during the exercise. If necessary, hand touches or acoustic stimuli were used to force the animals to continue training.

Table 1. The aerobic training program

\begin{tabular}{lcccccc}
\hline Practice variable & $\begin{array}{c}\text { Week } \\
1\end{array}$ & $\begin{array}{c}\text { Week } \\
2\end{array}$ & $\begin{array}{c}\text { Week } \\
3\end{array}$ & $\begin{array}{c}\text { Week } \\
4\end{array}$ & $\begin{array}{c}\text { Week } \\
5\end{array}$ & $\begin{array}{c}\text { Week } \\
6\end{array}$ \\
\hline Speed $(\mathrm{m} / \mathrm{min})$ & 10 & 10 & $14-15$ & $14-15$ & $17-18$ & $17-18$ \\
Duration $(\mathrm{min})$ & 10 & 20 & 20 & 30 & 30 & 40 \\
\hline
\end{tabular}

Berberine chloride: Berberine chloride supplement was administrated every day at a specific time using gavage. In this study, doses of 15 and $30 \mathrm{mg} / \mathrm{kg}$ were used based on EC50 (50\% effective concentration) of the complementary. In groups that did aerobic training, the drug was administrated through gavage one hour before exercises. Drug administration was continued in days that the animals did not do physical activities.

Sacrifice and sampling: Briefly, $48 \mathrm{~h}$ after the last exercise session and after $12 \mathrm{~h}$ of fasting, samples were collected from control and treatment groups. To collect the samples, rats were initially anesthetized using intraperitoneal (IP) injection of a combination of ketamine $(30-50 \mathrm{mg} / \mathrm{kg}$ ) and xylazine $(3-5 \mathrm{mg} / \mathrm{kg}$ ). Then, the chest of the animals was split and blood was collected directly from the heart. Blood was immediately poured into tubes containing ethylene diamine tetra acetic acid (EDTA). Samples were centrifuged at $3000 \mathrm{rpm}$ for $15 \mathrm{~min}$ and plasma was stored at $-80{ }^{\circ} \mathrm{C}$ until use.

Biochemical assays: A commercial kit (Cat No. ZB-10135S-R9648; Zellbio, Germany) with a sensitivity of $0.05 \mathrm{ng} / \mathrm{l}$ was used for testing plasma IL-6 and another commercial kit (Cat. No: 865,000.096; Diaclone, France) with a sensitivity of less than $15 \mathrm{pg} / \mathrm{ml}$ for TNF- $\alpha$. Blood Glucose was assessed using the glucocard-01 device (ARKRAY, Japan). Furthermore, blood glucose, BW and body mass index (BMI) was measured at the beginning of Week 1 and end of Week 6.

Statistical analysis: Data were analyzed using SPSS software v.25 (IBM Analytics, USA). The Kolmogorov-Smirnov test was used to show the normal distribution of the samples. For the comparison of the groups, two-way ANOVA and Tukey's post hoc test were used. Results were presented as mean $\pm \mathrm{SD}$ (standard deviation) and significant differences were reported when $P<0.05$.

\section{Results}

Changes in BW and BMI have been shown in Table 2. Blood glucose in the diabetic control group was significantly higher than that in the normal control group $(P<0.05)$, which indicated the successful induction of diabetes with STZ. Based on the results from two-way ANOVA, neither aerobic training alone nor berberine chloride alone included significant effects on blood glucose in diabetic rats 
$(P>0.05)$. However, with the intervention of these two variables (aerobic training and berberine chloride with doses of 15 and $30 \mathrm{mg} / \mathrm{kg}$ ), blood glucose significantly decreased $(P<0.05)$ (table 3$)$. A dose of $30 \mathrm{mg} / \mathrm{kg}$ of berberine chloride included greater effects on decreasing blood glucose, compared to a dose of $15 \mathrm{mg} / \mathrm{kg}$ of berberine chloride (Fig. 1).

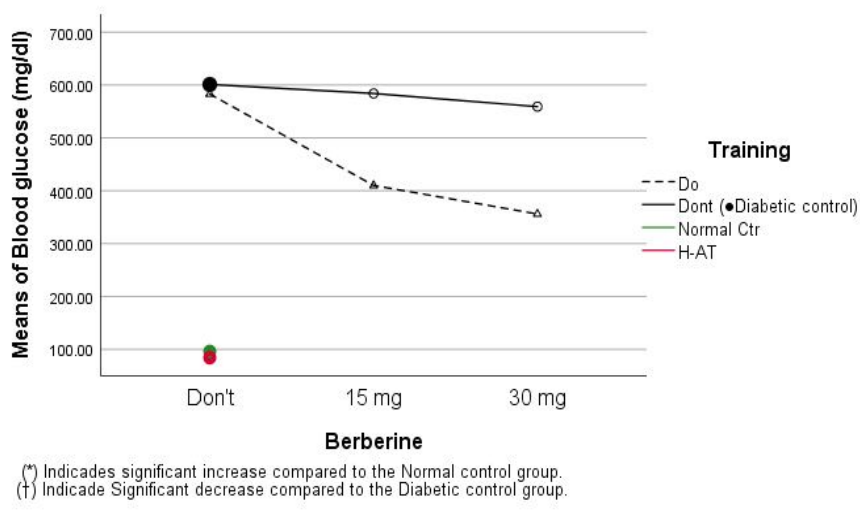

Figure 1. Blood glucose changes in the study groups

The IL-6 in the diabetic control group was significantly higher than that in the normal control group $(P<0.05)$. Consumption of $15 \mathrm{mg} / \mathrm{kg}$ of berberine chloride [D-Br $(15 \mathrm{mg})]$ included no significant effects on the increase or decrease in IL-6, compared to the diabetic control group. Consumption of $30 \mathrm{mg} / \mathrm{kg}$ of berberine chloride [D-Br $(30 \mathrm{mg})$ ] significantly decreased IL-6, compared to the diabetic control group (Fig. 2). The IL-6 slightly increased in diabetic groups that simultaneously received berberine chloride and aerobic training, compared to that in the diabetic control group. However, this increase was not statistically significant $(P>0.05)$ (table 3$)$. Plasma IL-6 was significantly higher in the health-trained group (H-AT) than that in other groups.

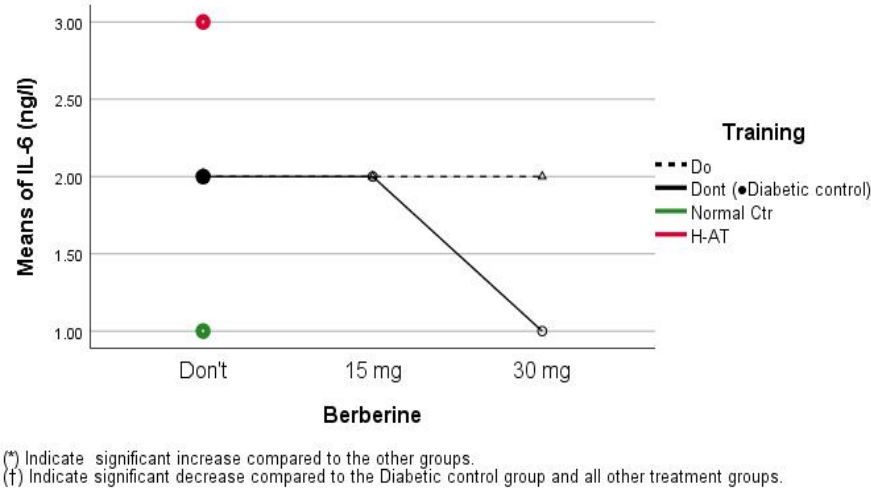

Figure 2. Changes in IL-6 of plasma in the study groups

Plasma TNF- $\alpha$ increased significantly in the diabetic control group, compared to that in the normal control group $(P<0.05)$. Furthermore, TNF- $\alpha$ decreased significantly in all treatment groups compared to that in the diabetic control group $(P<0.05)$. However, the interactive effect of the two variables (aerobic training and berberine chloride) was greater resulting in further the decreases in plasma TNF- $\alpha$. Moreover, a dose of $30 \mathrm{mg} / \mathrm{kg}$ of berberine chloride was more effective than a dose of $15 \mathrm{mg} / \mathrm{kg}$ of the chemical (Fig. 3).

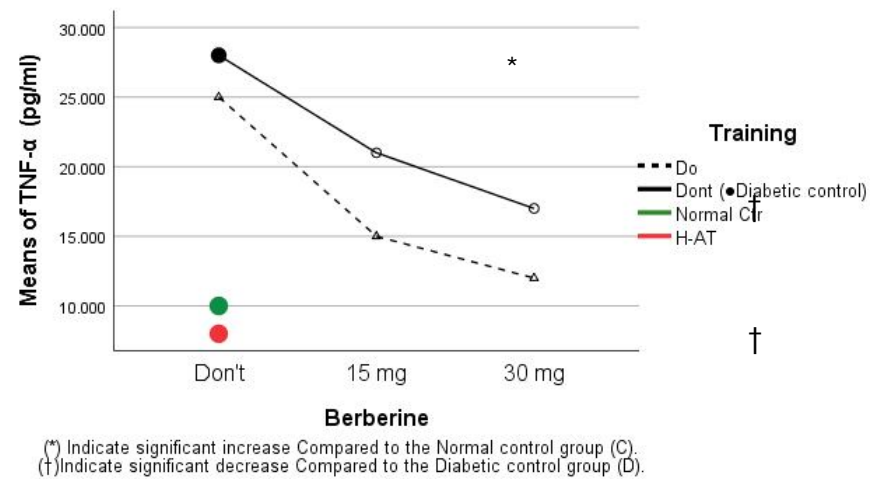

Figure 3. Changes in TNF- $\alpha$ of plasma in the study groups

Table 2. Initial and final body weights and body mass indices in study groups receiving various doses of berberine chloride

\begin{tabular}{|c|c|c|c|c|c|c|c|c|c|}
\hline \multirow[b]{2}{*}{ variable } & \multirow[b]{2}{*}{ week } & \multicolumn{8}{|c|}{ Group } \\
\hline & & $\mathrm{C}$ & $\mathrm{D}$ & $\begin{array}{c}\mathrm{D}-\mathrm{Br} \\
(15 \mathrm{mg})\end{array}$ & $\begin{array}{c}\mathrm{D}-\mathrm{Br} \\
(30 \mathrm{mg})\end{array}$ & D-AT & $\begin{array}{c}\text { D-AT-Br } \\
(15 \mathrm{mg})\end{array}$ & $\begin{array}{c}\text { D-AT-Br } \\
(30 \mathrm{mg})\end{array}$ & H-AT \\
\hline \multirow[t]{2}{*}{ BW (gr) } & 1 & $283.63 \pm 18.20$ & $285.12 \pm 13.37$ & $283.81 \pm 21.84$ & $281.57 \pm 14.04$ & $281.78 \pm 3.01$ & $283.63 \pm 5.79$ & $282.78 \pm 17.05$ & $282.80 \pm 7.26$ \\
\hline & 6 & $343.87 \pm 21.48$ & $198.57 \pm 4.47$ & $228.81 \pm 10.65$ & $283.88 \pm 10.05^{*}$ & $205.36 \pm 11.59$ & $289.63 \pm 7.95 *$ & $323.85 \pm 18.07^{*}$ & $354.56 \pm 16.63$ \\
\hline BMI & 1 & $0.63 \pm 0.02$ & $0.61 \pm 0.02$ & $0.60 \pm 0.01$ & $0.62 \pm 0.03$ & $0.61 \pm 0.01$ & $0.60 \pm 0.01$ & $0.60 \pm 0.02$ & $0.61 \pm 0.01$ \\
\hline$\left(\mathrm{g} / \mathrm{cm}^{2}\right)$ & 6 & $0.64 \pm 0.0$ & $0.46 \pm 0.03$ & $0.45 \pm 0.03$ & $0.50 \pm 0.03$ & $0.48 \pm 0.06$ & $0.61 \pm 0.01^{\mathfrak{f}}$ & $0.62 \pm 0.02^{\mathfrak{f}}$ & $0.65 \pm 0.02$ \\
\hline
\end{tabular}

Values include means \pm SD assayed by two-way ANOVA and Tukey's post hoc test; significant differences were seen between the experimental groups;

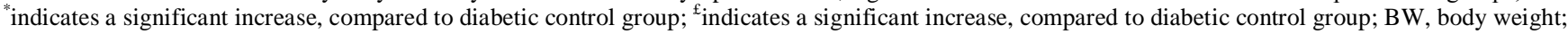
BMI, body mass index 
Table 3: two-way analysis of variance

\begin{tabular}{lllll}
\hline Dependent variable & Independent variable & F & Sig & Eta \\
\hline \multirow{3}{*}{ Glucose } & Aerobic training & 91.761 & 0.076 & 0.286 \\
& Berberine chloride & 88.555 & 0.081 & 0.214 \\
\hdashline-1 & Aerobic training* Berberine chloride & 110.244 & 0.001 & 0.797 \\
\hline \multirow{2}{*}{ IL-6 } & Aerobic training & 33.753 & 0.070 & 0.277 \\
& Berberine chloride & 3.072 & 0.001 & 0.842 \\
\hdashline & Aerobic training* Berberine chloride & 9.394 & 0.062 & 0.441 \\
\hline \multirow{2}{*}{ TNF- $\alpha$} & Aerobic training & 165.237 & 0.001 & 0.090 \\
& Berberine chloride & 84.806 & 0.001 & 0.478 \\
& Aerobic training* Berberine chloride & 180.555 & 0.001 & 0.990 \\
\hline
\end{tabular}

Table 4. Pearson correlation coefficient between the variables

\begin{tabular}{lccc}
\hline Variable & Variable & Pearson correlation & Significance \\
\hline BW & Blood glucose & $-.838^{* * *}$ & 0.001 \\
BW & TNF- $\alpha$ & $-.911^{* * *}$ & 0.001 \\
BW & BMI & $.858^{* *}$ & 0.001 \\
BMI & TNF- $\alpha$ & $-.819^{* *}$ & 0.001 \\
BMI & Blood glucose & $-.848^{* *}$ & 0.001 \\
Blood glucose & TNF- $\alpha$ & $.876^{* *}$ & 0.001 \\
\hline ***orrelation is significant at 0.001 levels; BW, body weight; BMI, body mass index &
\end{tabular}

\section{Disc ussion}

At the end of 6 weeks, blood plasma glucose level significantly decreased in the groups that received Berberine chloride and Aerobic Training Simultaneously compared to the diabetic control group, but in other treatment groups, this reduction was not significant. The Results suggested that berberine administration at indicated doses (15 and 30 $\mathrm{mg} / \mathrm{kg} / \mathrm{d}$ ) and aerobic training alone did not significantly affect the mean blood glucose of the experimental rats, but the simultaneous intervention of these two variables has a significant effect on decreased blood glucose in diabetic mice. Normally, blood glucose in type 1 diabetic patients decreases during the aerobic exercises but increases again (33), which is due to the insulin deficiency in the body. Reaven and Chang concluded that the exercise exerts a decrease in blood glucose (34). Exercise training enhances insulin sensitivity in normal rats $(24,35)$ and improves carbohydrate and fat metabolism abnormalities in type 1 diabetic subjects (34). Effects of the exercise training increase the efficiency of insulin-stimulated glucose disposal by the muscles (34). Based on the results from the current study and other studies, aerobic training alone possibly cannot lower blood glucose for a long time in type 1 diabetes. However, berberine was shown to be beneficial for the functional recovery of the Langerhans Islets in diabetes or prediabetes (36). Results from studies showed that berberine supplementation significantly increased the number of
Langerhans Islets (37). Results from another study indicated that berberine decreased serum blood glucose in a dose-dependent manner after 14 weeks of berberine oral supplementation. However, blood glucose was not significantly changed after seven weeks (7). Considering the effects of berberine on Langerhans Islets the cells and those of aerobic training on insulin sensitivity, it can be concluded from the present study that the interactive effect of these two variables results in a significant decrease in the blood glucose.

In the present study, plasma IL-6 in the diabetic control group increased significantly, compared to that in the normal control group. Cytokines, as one of the intracellular signaling molecules, cause the development and activation of immune cells, especially in autoimmune diseases, such as type 1 diabetes. Moreover, cytokines may serve as additional biomarkers of type 1 diabetes. Cytokines can provide valuable information on the pathways involved in the regulation of type 1 diabetes processes (3). The IL-6, a multifunctional cytokine, is secreted by $\mathrm{T}$ cells and macrophages and stimulates immune responses in inflammations and infections (38). In the current study, plasma IL-6 significantly decreased in the group that received $30 \mathrm{mg} / \mathrm{kg}$ of berberine chloride alone [D-Br $(30 \mathrm{mg} / \mathrm{kg})]$, compared to that in other treatment groups. Previous studies have shown that berberine chloride negatively regulates proinflammatory cytokines such as IFN- $\gamma$, TNF- $\alpha$, and 
IL-6 in animal models $(19,20)$.In the present study, a dose of $30 \mathrm{mg} / \mathrm{kg}$ of berberine, reduced the level of plasma IL-6 to the level of the normal control group. However, a dose of $15 \mathrm{mg} / \mathrm{kg}$ could not decrease blood IL-6. Furthermore, in health trained group (HAT), IL-6 significantly increased, compared to that in all other groups. The IL- 6 increased in all trained groups, compared to that in untrained groups. A study has shown that circulating IL-6 increases in an exponential mode (up to 100-fold) in response to exercises (25), which may occur due to the release of IL-6 from contractile muscles (39). Hiscock et al. provided definitive evidence that myocytes per se are major sources of contraction induced IL-6 (39). In 2000, Steensberg et al. published the first article demonstrating that most of IL-6 seen in blood circulation are likely derived from contracting limbs (40). Plasma concentrations of IL-6 have been known to increase considerably during physical activities. Studies have demonstrated that IL-6 is first produced by contracting skeletal muscles and then released into the blood circulation (8). An accompanying editorial by Gleeson suggests that muscle-derived IL-6 includes metabolic roles (41). Moreover, contractioninduced increases in IL-6 may result in activation of anti-inflammatory pathways and increase endogenous glucose production and clearance. These data provide the first evidence that skeletal muscles can release substances capable of modulating metabolic processes (8). The IL-6 increases insulin sensitivity, glucose transporter type-4 translocation, and glucose uptake in human muscle fibers (42) and enhances fat oxidation in skeletal muscles via the activation of the AMPK pathway (43). In fact, myokines exert their antiinflammatory effects by inhibiting effects of TNF- $\alpha$ and IL-1 $\beta$ as well as activating IL-1ra and IL-10 and thereby improve conditions of diabetes $(46,47)$.

Another cytokine, TNF- $\alpha$, is closely linked to metabolic disorders and diabetes. This cytokine was originally identified as an endogenous factor that influenced energy balance and was associated with weight loss, hypermetabolism and increased resting energy expenditure in infectious or malignant diseases (48, 49). In type 1 diabetes, TNF- $\alpha$ was found to involve in autoimmune processes leading to beta-cell damages $(10,42)$. Furthermore, TNF- $\alpha$ has been shown to increase the binding of molecules and activate macrophages, resulting in the development of type 1 diabetes (48). In the current study, plasma
TNF- $\alpha$ was significantly higher in the diabetic control group than that in the normal control group. This possibly occurred due to induced diabetes with STZ. Furthermore, plasma TNF- $\alpha$ decreased in all treatment groups, compared to that in the diabetic control group. Berberine alone with the doses of 15 and $30 \mathrm{mg} / \mathrm{kg}$ significantly decreased TNF- $\alpha$ in diabetic mice while aerobic training alone could not significantly decrease plasma TNF- $\alpha$. Plasma TNF- $\alpha$ decreased significantly in groups that received berberine chloride and aerobic training simultaneously, compared to that in other treatment groups (Figure 4). Based on the literature reviews, blood IL-6 increases in response to exercises. The released IL-6 from contractile muscles acts as an antiinflammatory cytokine (myokine). Moreover, aerobic training inhibits TNF- $\alpha$ production and hence decreases inflammation (49).

\section{Conclusion}

Based on the results from the current study, aerobic training and berberine synergistically affect blood glucose, IL-6, and TNF- $\alpha$ in type-1 diabetic male Wistar rats. Therefore, if berberine chloride is used at the same time that aerobic training is carried out, better results will be achieved. Furthermore, a dose of $30 \mathrm{mg} / \mathrm{kg}$ of berberine was more effective than a dose of $15 \mathrm{mg} / \mathrm{kg}$. Higher doses of berberine chloride or longer times of aerobic training possibly include better results. Further studies are necessary to prove this hypothesis.

\section{Acknowledgement}

We wish to thank Dr. Fatemeh Zare Mehrjerdi who helped us in all steps of this study.

\section{Financial disclosure}

The authors declared no financial interest.

\section{Funding/Support}

This study was the result of a doctorate thesis in Exercise's Physiology approved by Department of Exercise's Physiology, Islamic Azad University, Central Branch, Tehran, Iran.

\section{References}

1. Dailey G. Overall mortality in diabetes mellitus: where do we stand today? Diabetes Technol Ther. 2011;13(S1):S-65.

2. Ferreira-Hermosillo A, Molina-Ayala M, RamírezRentería C, Vargas G, Gonzalez B, Isibasi A, et al. Inflammatory cytokine profile associated with metabolic syndrome in adult patients with type 1 
diabetes. J Diabetes Res. 2015;2015.

3. Alnek K, Kisand K, Heilman K, Peet A, Varik K, Uibo R. Increased blood levels of growth factors, proinflammatory cytokines, and Th17 cytokines in patients with newly diagnosed type 1 diabetes. PLoS One. 2015;10(12):e0142976.

4. Pestana RMC, Domingueti CP, Duarte RCF, Fóscolo RB, Reis JS, Rodrigues AMS, et al. Cytokines profile and its correlation with endothelial damage and oxidative stress in patients with type 1 diabetes mellitus and nephropathy. Immunol Res. 2016;64(4):951-60.

5. Talaat IM, Nasr A, Alsulaimani AA, Alghamdi $\mathrm{H}$, Alswat KA, Almalki DM, et al. Association between type 1 , type 2 cytokines, diabetic autoantibodies and 25-hydroxyvitamin $\mathrm{D}$ in children with type 1 diabetes. $\mathbf{J}$ Endocrinol Invest. 2016;39(12):1425-34.

6. Petersen AMW, Pedersen BK. The anti-inflammatory effect of exercise. J Appl Physiol. 2005;98(4):1154-62.

7. Febbraio MA, Pedersen BK. Muscle-derived interleukin-6: mechanisms for activation and possible biological roles. FASEB J. 2002;16(11):1335-47.

8. Febbraio MA, Pedersen BK. Contraction-induced myokine production and release: is skeletal muscle an endocrine organ? Exerc Sport Sci Rev. 2005;33(3):1149 .

9. Pedersen BK, Steensberg A, Keller P, Keller C, Fischer $\mathrm{C}$, Hiscock $\mathrm{N}$, et al. Muscle-derived interleukin-6: lipolytic, anti-inflammatory and immune regulatory effects. Pflügers Arch. 2003;446(1):9-16.

10. Plaisance EP, Grandjean PW. Physical activity and high-sensitivity C-reactive protein. Sport Med. 2006;36(5):443-58.

11. Thomas HE, Darwiche R, Corbett JA, Kay TWH. Evidence that $\beta$ cell death in the nonobese diabetic mouse is Fas independent. J Immunol. 1999;163(3):1562-9.

12. Green DR, Reed JC. Mitochondria and apoptosis. Science [Internet]. 1998 Aug 28;281(5381):1309-12. Available from:

http://www.sciencemag.org/cgi/doi/10.1126/science.28 1.5381.1309

13. NING G, HONG J, BI Y, GU W, ZHANG Y, ZHANG $\mathrm{Z}$, et al. Progress in diabetes research in China. J Diabetes [Internet]. 2009 Sep;1(3):163-72. Available from: http://www.ncbi.nlm.nih.gov/pubmed/20923535

14. Lin W-C, Lin J-Y. Five Bitter Compounds Display Different Anti-inflammatory Effects through Modulating Cytokine Secretion Using Mouse Primary Splenocytes in Vitro. J Agric Food Chem [Internet]. 2011 Jan 12;59(1):184-92. Available from: http://pubs.acs.org/doi/abs/10.1021/jf103581r

15. Wang Y, Campbell T, Perry B, Beaurepaire C, Qin L. Hypoglycemic and insulin-sensitizing effects of berberine in high-fat diet- and streptozotocin-induced diabetic rats. Metabolism [Internet]. 2011
Feb;60(2):298-305. Available from: http://linkinghub.elsevier.com/retrieve/pii/S002604951 0000594

16. Wang Y, Campbell T, Perry B, Beaurepaire C, Qin L. Hypoglycemic and insulin-sensitizing effects of berberine in high-fat diet- and streptozotocin-induced diabetic rats. Metabolism. 2011 Feb;60(2):298-305.

17. Ikram M. A review on the chemical and pharmacological aspects of genus Berberis. Planta Med. 1975;28(8):353-8.

18. Vuddanda PR, Chakraborty S, Singh S. Berberine: a potential phytochemical with multispectrum therapeutic activities. Expert Opin Investig Drugs. 2010; 19(10):1297-307.

19. Enk R, Ehehalt R, Graham JE, Bierhaus A, Remppis A, Greten HJ. Differential effect of Rhizoma coptidis and its main alkaloid compound berberine on TNF- $\alpha$ induced NFאB translocation in human keratinocytes. J Ethnopharmacol. 2007;109(1):170-5.

20. Ren Y, Lu L, Guo TB, Qiu J, Yang Y, Liu A, et al. Novel immunomodulatory properties of berbamine through selective down-regulation of STAT4 and action of IFN- $\gamma$ in experimental autoimmune encephalomyelitis. J Immunol. 2008;181(2):1491-8.

21. Chandirasegaran G, Elanchezhiyan C, Ghosh K, Sethupathy S. Berberine chloride ameliorates oxidative stress, inflammation and apoptosis in the pancreas of Streptozotocin induced diabetic rats. Biomed Pharmacother [Internet]. 2017 Nov;95:175-85. Available from:

http://dx.doi.org/10.1016/j.biopha.2017.08.040

22. Moghaddam HK, Baluchnejadmojarad T, Roghani M, Khaksari M, Norouzi P, Ahooie M, et al. Berberine ameliorate oxidative stress and astrogliosis in the hippocampus of STZ-induced diabetic rats. Mol Neurobiol. 2014;49(2):820-6.

23. Pan X-R, Li G-W, Hu Y-H, Wang J-X, Yang W-Y, An $\mathrm{Z}-\mathrm{X}$, et al. Effects of Diet and Exercise in Preventing NIDDM in People With Impaired Glucose Tolerance: The Da Qing IGT and Diabetes Study. Diabetes Care [Internet]. 1997 Apr 1;20(4):537 LP-544. Available from:

http://care.diabetesjournals.org/content/20/4/537.abstrac $\mathrm{t}$

24. Berger M, Kemmer FW, Becker $\mathrm{K}$, Herberg L, Schwenen M, Gjinavci A, et al. Effect of physical training on glucose tolerance and on glucose metabolism of skeletal muscle in anaesthetized normal rats. Diabetologia. 1979;16(3):179-84.

25. Pedersen BK, Akerstrom TC, Nielsen AR, Fischer CP, Akerström TCA, Nielsen AR, et al. Role of myokines in exercise and metabolism. J Appl Physiol [Internet]. 2007;103(3):1093-8. Available from: http://www.ncbi.nlm.nih.gov/pubmed/17347387

26. Pedersen BK. Anti-inflammatory effects of exercise $\square$ : role in diabetes and cardiovascular disease. :1-12. 
27. Ostrowski K, Schjerling P, Pedersen BK. Physical activity and plasma interleukin-6 in humans-effect of intensity of exercise. Eur J Appl Physiol. 2000;83(6):512-5.

28. Steensberg A, Fischer CP, Keller C, Møller K, Pedersen BK. IL-6 enhances plasma IL-1ra, IL-10, and cortisol in humans. Am J Physiol Metab. 2003;285(2):E433-7.

29. Ostrowski K, Rohde T, Zacho M, Asp S PB. Evidence That IL-6 is produced in skalatal muscle during intense long-term muscle activity. Copenhagen muscle Res Cent. 1997;7-8.

30. Salamat KM, Azarbayjani MA, Yusof A, Dehghan F. The response of pre-inflammatory cytokines factors to different exercises (endurance, resistance, concurrent) in overweight men. Alexandria J Med [Internet]. 2016 Dec;52(4):367-70. Available from: http://dx.doi.org/10.1016/j.ajme.2015.12.007

31. Savi M, Bocchi L, Mena P, Dall'Asta M, Crozier A, Brighenti F, et al. In vivo administration of urolithin A and $B$ prevents the occurrence of cardiac dysfunction in streptozotocin-induced diabetic rats. Cardiovasc Diabetol [Internet]. 2017 Jul;16(1):80. Available from: https://doi.org/10.1186/s12933-017-0561-3

32. Chae C-H, Jung S-L, An S-H, Jung C-K, Nam S-N, Kim H-T. Treadmill exercise suppresses muscle cell apoptosis by increasing nerve growth factor levels and stimulating p-phosphatidylinositol 3-kinase activation in the soleus of diabetic rats. J Physiol Biochem. 2011;67(2):235-41.

33. Yardley JE, Kenny GP, Perkins BA, Riddell MC, Balaa N, Malcolm J, et al. Resistance Versus Aerobic Exercise: Acute effects on glycemia in type 1 diabetes. Diabetes Care [Internet]. 2013 Mar 1;36(3):537-42. Available from:

http://care.diabetesjournals.org/cgi/doi/10.2337/dc120963

34. Reaven GM, Chang F. Effect of exercise-training on the metabolic manifestations of streptozotocin-induced diabetes in the rat. Diabetologia. 1981;21(4):415-7.

35. Mondon CE, Dolkas CB, Reaven GM. Site of enhanced insulin sensitivity in exercise-trained rats at rest. Am J Physiol [Internet]. 1980;239(3):169-77. Available from: http://www.ncbi.nlm.nih.gov/pubmed/7001913

36. Yin J, Hu R, Chen M, Tang J, Li F, Yang Y, et al. Effects of berberine on glucose metabolism in vitro. Metabolism. 2002;51(11):1439-43.

37. Chueh WH, Lin JY. Protective effect of berberine on serum glucose levels in non-obese diabetic mice. Int Immunopharmacol [Internet]. 2012;12(3):534-8. Available from:

http://dx.doi.org/10.1016/j.intimp.2012.01.003

38. Yin Y-W, Sun Q-Q, Zhang B-B, Hu A-M, Wang Q, Liu $\mathrm{H}-\mathrm{L}$, et al. The lack of association between interleukin-
6 gene $-174 \mathrm{G} / \mathrm{C}$ polymorphism and the risk of type 1 diabetes mellitus: A meta-analysis of 18,152 subjects. Gene. 2013;515(2):461-5.

39. Hiscock N, Chan MHS, Bisucci T, Darby IA, Febbraio MA. Skeletal myocytes are a source of interleukin-6 mRNA expression and protein release during contraction: evidence of fiber type specificity. FASEB J. 2004;18(9):992-4.

40. Steensberg A, Hall G, Osada T, Sacchetti M, Saltin B, Pedersen BK. Production of interleukin $\square 6$ in contracting human skeletal muscles can account for the exercise $\square$ induced increase in plasma interleukin $\square$ 6. J Physiol. 2000;529(1):237-42.

41. Gleeson M. Interleukins and exercise. J Physiol. 2000;529(1):1.

42. Carey AL, Steinberg GR, Macaulay SL, Thomas WG, Holmes AG, Ramm G, et al. Interleukin-6 increases insulin-stimulated glucose disposal in humans and glucose uptake and fatty acid oxidation in vitro via AMP-activated protein kinase. Diabetes. 2006;55(10):2688-97.

43. Kelly M, Gauthier M, Saha AK, Ruderman NB. Activation of AMP-Activated Protein Kinase by Interleukin-6 in Rat Skeletal Muscle. Diabetes. 2009;58(September):1953-60.

44. Yang X-D, Tisch R, Singer SM, Cao ZA, Liblau RS, Schreiber RD, et al. Effect of tumor necrosis factor alpha on insulin-dependent diabetes mellitus in NOD mice. I. The early development of autoimmunity and the diabetogenic process. J Exp Med. 1994;180(3):9951004.

45. Heidenreich S, Weyers M, Gong J-H, Sprenger H, Nain M, Gemsa D. Potentiation of lymphokine-induced macrophage activation by tumor necrosis factor-alpha. $\mathbf{J}$ Immunol. 1988;140(5):1511-8.

46. Beutler B, Cerami A. Cachectin (tumor necrosis factor): a macrophage hormone governing cellular metabolism and inflammatory response. Endocr Rev. 1988;9(1):5766.

47. Sarraf P, Frederich RC, Turner EM, Ma G, Jaskowiak NT, Rivet DJ, et al. Multiple cytokines and acute inflammation raise mouse leptin levels: potential role in inflammatory anorexia. J Exp Med. 1997;185(1):171-6.

48. Mueller C, Held W, Imboden MA, Carnaud C. Accelerated $\beta$-cell destruction in adoptively transferred autoimmune diabetes correlates with an increased expression of the genes coding for TNF- $\alpha$ and granzyme $\mathrm{A}$ in the intra-islet infiltrates. Diabetes. 1995;44(1):112-7.

49. Lee YS, Kim WS, Kim KH, Yoon MJ, Cho HJ, Shen Y, et al. AMP-Activated Protein Kinase With Beneficial Metabolic Effects in Diabetic and Insulin-Resistant States. 2006;55(August). 